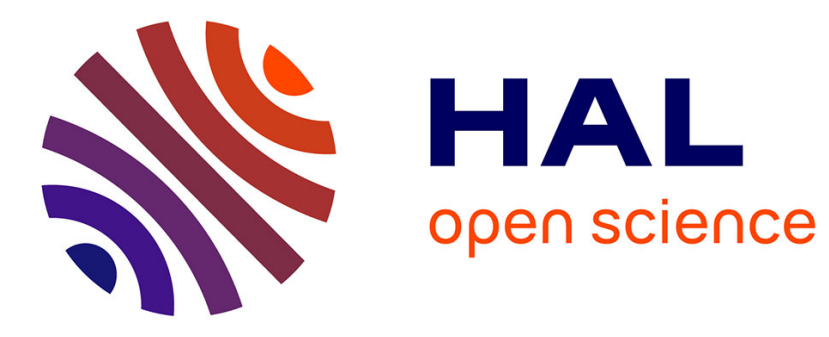

\title{
Destructive Obedience Without Pressure
}

Martial Mermillod, Victorien Marchand, Johan Lepage, Laurent Bègue, Michael Dambrun

\section{To cite this version:}

Martial Mermillod, Victorien Marchand, Johan Lepage, Laurent Bègue, Michael Dambrun. Destructive Obedience Without Pressure: Beyond the Limits of the Agentic State . Social psychology, 2015, 46 (6), pp.345 - 351. 10.1027/1864-9335/a000251 . hal-01415561

\section{HAL Id: hal-01415561 \\ https://hal.science/hal-01415561}

Submitted on 13 Dec 2016

HAL is a multi-disciplinary open access archive for the deposit and dissemination of scientific research documents, whether they are published or not. The documents may come from teaching and research institutions in France or abroad, or from public or private research centers.
L'archive ouverte pluridisciplinaire HAL, est destinée au dépôt et à la diffusion de documents scientifiques de niveau recherche, publiés ou non, émanant des établissements d'enseignement et de recherche français ou étrangers, des laboratoires publics ou privés. 


\title{
Destructive Obedience Without Pressure
}

\section{Beyond the Limits of the Agentic State}

\author{
Martial Mermillod, ${ }^{1,2}$ Victorien Marchand, ${ }^{3}$ Johan Lepage, ${ }^{4}$ Laurent Begue, ${ }^{4}$ \\ and Michael Dambrun ${ }^{3}$ \\ ${ }^{1}$ Univ. Grenoble Alpes, LPNC, Grenoble, France, ${ }^{2}$ Institut Universitaire de France, Paris, France, \\ ${ }^{3}$ Clermont Université, Université Blaise Pascal, CNRS, LAPSCO, Clermont-Ferrant, France, \\ ${ }^{4}$ Univ. Grenoble-Alpes, LIP, Grenobles, France
}

\begin{abstract}
Studies on obedience to authority highlight the power of the situation by showing how an experimental setting can trap participants and force them to commit acts contrary to their values (Bocchiaro \& Zimbardo, 2010). The source of obedience has generally been represented by an institutional scientific authority. In the present experiment, we tested a more widespread form of authority: a managerial authority implemented in the form of an administrative violence paradigm (Meeus \& Raaijmakers, 1986). Specifically, we compared two forms of authority: obedience to authority as manipulated by Meeus and Raaijmakers (1986), where the requests are made in an authoritarian manner, and compliance without pressure, where the participant is told that he is free to do what is requested (Enzle \& Harvey, 1982). The results illustrate that a substantial level of obedience can be elicited even in the absence of explicit authoritarian pressure.
\end{abstract}

Keywords: obedience to authority, compliance without pressure, agentic state

It is now more than 50 years since Milgram published the first experimental study on obedience to authority (Milgram, 1963). Despite the recent exciting development in the study of obedience, including new theoretical perspectives (e.g., discourse analysis; Burger, Girgis, \& Manning, 2011; Gibson, 2013), innovative research procedures (e.g., virtual reality; Dambrun \& Vatiné, 2010; Slater et al., 2006), and interest for the neural underpinnings of destructive obedience (Cheetham, Pedroni, Antley, Slater, \& Jäncke, 2009), there is still a fundamental debate on the social significance of the Milgram experiments (e.g., Reicher, Haslam, \& Smith, 2012; Werhane, Pincus Hartman, Archer, Englehardt, \& Pritchard, 2013). According to Milgram (1974), "the essence of obedience consists in the fact that a person comes to view themselves as the instrument for carrying out another person's wishes, and they therefore no longer see themselves as responsible for their actions. Once this critical shift of viewpoint has occurred in the person, all of the essential features of obedience follow." But as noted by Reicher and Haslam (2011), "even those who are most sympathetic to Milgram's work in general find his notion of an agentic state singularly unilluminating." Whereas a dominant viewpoint suggests that individuals obey due to a passive conformation to the authority's commands, recent findings suggest that participants' willingness to engage in destructive obedience is "a reflection not of simple obedience, but of active identification with the experimenter and his mission" (Reicher et al., 2012). Thus, according to these authors, destructive obedience is more meaningful (less "blind") than Milgram's agentic state model argues, and patterns of social identification play a key role in the obedience process.

Recent findings suggest that participants in the Milgram studies typically refuse to obey to direct order ("You have no other choice, you must go on"; Burger et al., 2011), and Reicher and Haslam (2011) argued that use of direct orders by authority dismantles the group relationship between participants and authority, and hence produces disobedience. However, several authors argued that coercive pressure is a key component of crimes of obedience. For example, Lankford (2009) argued that torture at Abu Ghraib implied coercive pressures on soldiers to obey: "For the guards and interrogators at $\mathrm{Abu}$ Ghraib, there was a great deal of coercive pressure to acquiesce to the authorizations for aggression, violence, and harsh interrogations. Although the threat of punishment for disobedience was usually implicit and unspoken, military personnel must have known that they would face severe consequences if they failed to follow orders."

Milgram's obedience experiments are mostly known for their illustration of the strength of the situation on human behavior (e.g., Berkowitz, 1999). Yet there is still a fundamental debate on the role of coercive pressure in the obedience process (e.g., Haslam \& Reicher, 2012; Kelman, 2006; Lankford, 2009). The key research question concerned the effects of the degree of pressure exerted by the authority 
on obedience behavior. While a social identity perspective predicts more obedience with a low level of coercive pressure, a more "traditional" approach predicts more obedience with a high level of coercive pressure.

\section{From the Milgram Obedience Experiments to the Utrecht Studies}

In the Milgram's obedience experiments (1963, 1974), members of the US general public volunteered to take part in a scientific study of memory. When they arrived at the laboratory, participants were told they will participate in an experiment on the effects of punishment on learning. They found themselves cast in the role of a "Teacher" and were ordered to administer increasingly severe electric shocks (from 15 to 450 volts in $15 \mathrm{~V}$ increments) to another person (the "Learner") every time he failed to recall the correct word in a previously learned pair. In the so-called "baseline" conditions (Conditions 1 and 5; Milgram, 1974), results revealed that $65 \%$ of the participants fully obeyed the destructive orders. As noted by Haslam and Reicher (2012), the Milgram's work “appeared to provide compelling evidence that normal well-adjusted men would be willing to kill a complete stranger simply because they were ordered to do so by an authority."

Because power in modern Western Societies is primarily exerted by the use of psychological violence (e.g., Elias, 1983), Meeus and Raaijmakers (1986) designed an "administrative obedience paradigm" in which they used a sequence of increasingly negative and denigrating remarks instead of a shock generator to punish the victim. In the socalled "Utrecht Studies," the victim was a person in longterm unemployment who had to pass a test to get a job, and participants were ordered to make him nervous and disturb him during the test after being told that they were participating in an experiment on the effects of psychological stress on test achievement. In order to do so, the participants had to enunciate a sequence of increasingly denigrating remarks about his performance. Because of this experimental procedure, the applicant failed the test and remained unemployed. The results revealed that more than $90 \%$ of the participants carried out these orders until the end of the procedure.

As emphasized by Haslam and Reicher (2012), much of the power of the experimental research on destructive obedience "derives from the fact that it appears to give empirical evidence to this claim that evil is banal." But it seems that the "Milgram's image of the banal participant delivering electric shocks has served to occlude the complexity and variability of his findings" (Reicher \& Haslam, 2011). Indeed, Milgram investigated 21 variants of his obedience paradigm (Milgram, 1974) which produced levels of obedience ranging from $0 \%$ to $100 \%$ as a function of context, and Milgram himself bemoans a common misinterpretation of his research due to the general focus on the occurrence of obedience rather than considering variation in its occurrence.
According to Reicher and Haslam (2011), participants do not only enter in agentic state, but "there is certainly nothing to suggest that variation in this state can explain variation in levels of obedience across different experiments."

\section{The Role of Coercive Pressure (vs. Compliance Without Pressure) in the Obedience Process}

Recent research suggests that the Milgram studies are less about people conforming slavishly to the will of authority "than about getting people to believe in the importance of what they are doing" (Haslam \& Reicher, 2012). For example, Burger et al. (2011) analyzed the participants' reactions to each of the experimenter's prods $(\times 4)$ in the Milgram experiments. According to these authors, while the fourth prod ("You have no other choice, you must go on") really sounds like an order, the first prod ("Please continue" or "Please go on"), the second prod ("The experiment requires that you continue"), and the third prod ("It is absolutely essential that you continue") sound like arguments for why the participants should continue (i.e., it is "important," "crucial" for the experiment). The authors found that "the more the experimenter's statement resembled an order, the less likely participants did what the experimenter wished." Moreover, not one participant "obeyed" when the only prod that the authors categorized as an explicit order was heard. By suggesting that participants tend to go along with the Experimenter only if he justifies the actions (in terms of the scientific benefits), these results "challenge interpretations of the obedience studies based on the notion that participants were following orders" (Burger et al., 2011).

Following a social identity perspective, Haslam and Reicher (2012) argued that the use of authoritarian orders may be counterproductive because it undermines a sense of shared identity and hence the motivation to cooperate. According to the authors, the "individuals' willingness to follow authorities is conditional on identification with the authority in question and an associated belief that the authority is right." Reicher et al. (2012) found empirical evidence that the Milgram experimental conditions that encouraged identification with the experimenter (and the scientific community) led participants to follow orders, while experimental conditions that encouraged identification with the victim (and the general community) led participants to refuse to obey.

Aside this approach, the legitimacy perspective provides several consistent arguments (e.g., Kelman, 2006; Kelman \& Hamilton, 1989). Kelman (2006) emphasized that in crimes of obedience (such as torture at Abu Ghraib), higher-level superiors may in fact not have issued specific orders to engage in these criminal acts, but they are the ones who formulate the policies. According to the author, the role of such a process of authorization "is strengthened by the fact that torturers, typically, are not just acting within 
a hierarchy in which they are expected to obey (..) but they are participating in an action that represents a transcendent mission. They have come to share the view of the authorities that the task they are engaged in serves a higher purpose that transcends any moral scruples they might bring to the situation."

To sum up, manipulating the degree of coercive pressure through the prods in an obedience paradigm should influence obedience. A "Compliance without pressure" condition should facilitate a sense of shared identity with the experimenter and then obedience (e.g., Haslam \& Reicher, 2012). Conversely, research on crimes of obedience (e.g., Lankford, 2009) predicts more obedience in a "Compliance with pressure" condition. The aim of our current study is to tease apart these two alternative hypotheses.

\section{Method}

\section{Active Role-Play}

The Milgram's obedience studies have been a target of criticism because of the deception involved (e.g., Miller, 1986). A dominant viewpoint is that deception should be used to increase experimental control (e.g., Weiss, 2001), but several authors argued that it could "raise participants' suspicions, prompt second-guessing of experimenters' true intentions, and ultimately distort behavior and endanger the control it is meant to achieve" (Hertwig \& Ortmann, 2008). Consistently, many studies devoid of deception have been conducted and demonstrate that alternatives are available (e.g., Gross \& Fleming, 1982). Interestingly for our purpose, results of active role-playing versions of obedience experiments have been found to have levels of obedience comparable to the original studies (e.g., Meeus \& Raaijmakers, 1995). More recently, several obedience studies using Immersive Virtual Environment Technology (IVET; Blascovich et al., 2002) found that participants responded to the situation at the subjective, behavioral, and physiological levels as if the victim and the shocks were real (e.g., Cheetham et al., 2009; Dambrun \& Vatiné, 2010; Slater et al., 2006). All in all, these studies demonstrate that the objective "reality" of pain is of secondary importance and that active role-play is a reliable method to study destructive obedience.

In order to test the role of the coercive pressure in the obedience process, we used a role-playing version of the administrative obedience paradigm. Moreover, participants and the victim were face-to-face in the same room (e.g., Bocchiaro \& Zimbardo, 2010).

\section{Participants}

Forty-six individuals participated in this experiment (38 female and 8 male; $M_{\text {age }}=21.02, S D=2.39$ ). Participants volunteered for the experiment in exchange for $15 €$. They were tested individually and were randomly assigned to one of the two experimental conditions ("Compliance without pressure" vs. "Compliance with pressure").

For ethical reasons, we selected participants omitting the persons who reported low ability to endure stress. Thus, participants had to fill out a brief questionnaire with two items: the first one was about participants' recent negative life events, and the second was about their perceived ability to endure an unpleasant or stressful situation. Using an 8 -point rating scale $(0=$ totally disagree to $7=$ totally agree), we systematically refused participants with a mean equal to or superior to 5 (scores about 5 meaning that they had a low ability to endure stress). The rejected participants $(\times 2)$ received the $15 €$ and were debriefed about the experiment.

\section{Procedure}

The experiment was conducted in accordance with the ethical principles of the statement of Helsinki and was supervised by a psychologist who debriefed and followed up each participant for one week after the experiment. The participants were greeted by the experimenter (male, 25 years, formal attire) and were told they were participating in a psychology experiment. First, participants were asked to complete a brief questionnaire assessing peritraumatic distress. We used 12 items $(\alpha=.51)$ from the Peritraumatic Distress Inventory (Brunet et al., 2001). Then, the participants were told that the experiment will follow "a role-playing game" logic: "All what will happen during the experiment will be simulated. You will interact with another person: this person is an actor that will simulate reactions to the experimental procedure. However, I ask you to behave as naturally as possible, in the same way as if everything was real."

The experimenter presented himself as a consultant for "Systemia Consulting" (a fictive Human Resources consulting firm), which has been approached by the University to evaluate its administrative employees every 2 years. In order to ensure the procedure impartiality, the University requested the presence of a student for each evaluation as an "independent observer."

Participants were told that the employees have to succeed in the test in order to keep their job. They were given an information booklet about the employee and were asked to acquaint themselves with the content. It was stated that the employee's superiors considered him to be hardworking and punctual.

The experimenter explained that during the test the employees have to process as many as possible forms in a given time by entering them in a computer without any mistakes. The role of the consultant was to check the employees' performance and to announce the number of mistakes. The computer was placed in front of the employee, the consultant was close to him, and the participants were sat in front of them. 
Table 1. Experimental procedure

Comments administered by the participant

Confederate's response

$<$ No comment $>$

Try to go faster next time.

Nod

$<$ No comment $>$

You have to go faster next time.

You are slow.

You are too slow.

If you want to keep your job, you'll have to go faster.

You want to continue working here with such results?

Obviously, you do not have your place in this administration.

$-$

"Yes" annoyed

Sigh

I am doing my best

Your remarks are stressing me, I am working less efficiently.

Please stop, you are making me do things wrong.

If you continue, I will lose my job!

Such incompetence is not acceptable.

Evaluation completed, the confederate leaves the room.

Before introducing the employee, the experimenter revealed the purpose of the test: due to budget cuts, the University has to dismiss several employees. In order to identify those who will be dismissed, the participants have to stress the employee by making negative remarks about his performance during the test. Then, they were given a notebook containing the stressful and denigrating remarks.

In the "Compliance with pressure" condition, participants were explicitly ordered by the consultant to enunciate all the remarks: "You have to enunciate all of these remarks very carefully, exactly as they are appeared in the notebook. You have to follow my instructions."

In the "Compliance without pressure" condition, the consultant insisted on the participant's "freedom of action": "You came here voluntarily, I totally trust you to make sure that this interview is successful."

Then, the consultant introduced the employee (a confederate - male, 25 years) and the experiment began. The employee had to process 10 files (Table 1). After each file, (i) the consultant announced the number of mistakes (prespecified), (ii) the participant had to enunciate the corresponding stressful remark, and (iii) the employee reacted verbally and physically (prespecified). The remarks were increasingly negative and denigrating, and both the employee stress and errors increased with the remarks (from 0 to 4 ).

When the participants refused (or hesitated) to formulate a remark, the consultant intervened with two consecutive injunctions (e.g., Burger et al., 2011; Dambrun \& Vatiné, 2010). In the "Compliance without pressure" condition, the prods were encouraging and stressed the participants' freedom:

1. "Can you read these remarks as they were written, please?"

2. "Of course, you can stop if you want, but you have done well so far, and it would be a shame to stop now."

In the "Compliance with pressure," the prods were authoritarian injunctions to achieve the procedure:

1. "Do what I told you, enunciate these remarks as they were written."
2. "You have to enunciate these remarks, you have no other choice."

If participants refused to obey the consultant after Prod 2, the experiment was terminated. Otherwise, the employee was thanked after the last files and left the room.

After the test, the participants were asked to complete a second questionnaire assessing peritraumatic distress, attribution of responsibility, and the "feeling of freedom of action." To assess peritraumatic distress, we used 12 items $(\alpha=.71)$ from the Peritraumatic Distress Inventory (Brunet et al., 2001). We used three items with a 7-point rating scale (from $0=$ not at all responsible to $6=$ fully responsible) to measure participants' perception of responsibility for themselves, the experimenter, and the employee. Finally, we assessed the "feeling of freedom of action" using one item with a 6-point rating scale.

\section{Obedience to Authority}

Obedience was measured in two ways. Absolute obedience was indicated by whether the participants made all the remarks $(0=$ not fully obedient, $1=$ fully obedient $)$. The relative obedience refers to the maximum number of stressful remarks made (from 0 to 10).

\section{Debriefing}

Finally, participants were reminded that the experience was a simulation and were informed about the well-being of the applicant before they met him in person. Participants were fully debriefed about the experiment and we ensured that participants did not leave the experiment with bad feelings about the experiment. Before being thanked and dismissed, participants were told to contact the experimenter if they had any questions or comments at any time. All the participants were contacted a week later. None of them regretted having participated. 


\section{Results}

We used one item with a 6-point scale to assess the credibility of the experiment $(M=3.45, S D=1.50)$. Most of the participants declared during the debriefing that they were deeply immersed in the situation and forgot the roleplaying. A $t$-test for paired samples with the peritraumatic distress as dependent variable revealed that the level of peritraumatic distress was higher after the experiment $(M=3.91, \quad S D=1.10)$ than before the experiment $(M=3.31, S D=0.80), t(43)=-4.39, p<0.001$. A $t$-test for independent samples with the "feeling of freedom" as a dependent variable revealed no significant difference between the two conditions (Table 2).

\section{Obedience to Authority}

Overall, $84 \%$ of the participants fully obeyed the consultant.

\section{Absolute Obedience}

We performed a binary logistic regression analysis with the degree of pressure (with vs. without pressure) as

Table 2. Behavioral data. ODA refers to the classical obedience to destructive authority situation; CWP refers to the compliance without pressure situation

\begin{tabular}{|c|c|c|c|c|}
\hline Subject number & Exp. group & Obedience until the end & Level of disobedience & Injunction number \\
\hline 1 & ODA & No & 10 & $7 \& 10$ \\
\hline 2 & ODA & Yes & & 0 \\
\hline 3 & ODA & Yes & & 0 \\
\hline 4 & ODA & Yes & & 0 \\
\hline 5 & ODA & Yes & & 0 \\
\hline 6 & ODA & Yes & & 8 \\
\hline 7 & ODA & Yes & & 0 \\
\hline 8 & ODA & Yes & & 0 \\
\hline 9 & ODA & Yes & & 0 \\
\hline 10 & ODA & Yes & & 0 \\
\hline 11 & ODA & Yes & & 0 \\
\hline 12 & ODA & Yes & & 0 \\
\hline 13 & ODA & Yes & & 0 \\
\hline 14 & ODA & Yes & & 0 \\
\hline 15 & ODA & Yes & & 0 \\
\hline 16 & ODA & Yes & & 2 \\
\hline 17 & ODA & Yes & & 0 \\
\hline 18 & ODA & Yes & & 0 \\
\hline 19 & ODA & Yes & & 0 \\
\hline 20 & ODA & Yes & & $7 \& 8$ \\
\hline 21 & ODA & Yes & & 0 \\
\hline 22 & ODA & Yes & & $8 \& 10$ \\
\hline 1 & CWP & Yes & & 0 \\
\hline 2 & CWP & No & 5 & 2 \\
\hline 3 & CWP & Yes & & 0 \\
\hline 4 & CWP & Yes & & 0 \\
\hline 5 & CWP & No & 5 & 2 \\
\hline 6 & CWP & No & 6 & 2 \\
\hline 7 & CWP & No & 6 & 2 \\
\hline 8 & CWP & Yes & & 0 \\
\hline 9 & CWP & Yes & & 0 \\
\hline 10 & CWP & Yes & & 0 \\
\hline 11 & CWP & Yes & & 0 \\
\hline 12 & CWP & Yes & & 7 \\
\hline 13 & CWP & Yes & & 0 \\
\hline 14 & CWP & Yes & & 0 \\
\hline 15 & CWP & Yes & & 0 \\
\hline 16 & CWP & Yes & & 0 \\
\hline 17 & CWP & No & 2 & 2 \\
\hline 18 & CWP & No & 6 & 2 \\
\hline 19 & CWP & Yes & & 0 \\
\hline 20 & CWP & Yes & & 0 \\
\hline 21 & CWP & Yes & & 0 \\
\hline 22 & CWP & Yes & & 8 \\
\hline
\end{tabular}


independent variable and binary scores of obedience as dependent variable. The results revealed a marginally significant effect, $B=.127, \mathrm{ES}=1.130, \quad W=3.336$, $p=.068$. It suggests that the level of obedience was higher in the "Compliance with pressure condition" $(96 \%)$ than in the "Compliance without pressure" condition (73\%).

\section{Relative Obedience}

A Mann-Whitney $U$-test ${ }^{1}$ was conducted to evaluate the hypothesis that the number of stressing remarks made by the participants was different according to the condition. The relative obedience was higher in the "Compliance with pressure" condition (average rank $=25.14$ ) than in the "Compliance without pressure" condition (average rank $=19.86), z=-2.139, p<.032$. Because our sample size was relatively small $(n=44)$, we performed a Monte Carlo analysis $(10,000$ samples and confidence intervals $=99 \%$ ). This analysis confirms the previous result $(p<.02$; IC: .016; .024). Participants in the "Compliance without pressure" condition disobeyed earlier than the participants in the "Compliance with pressure" condition.

\section{Attribution of Responsibility}

We performed $t$-tests for paired samples to compare the attribution of responsibility to the self, the victim, and the experimenter. Participants attributed lower responsibility to themselves $(M=3.05, S D=1.51)$ than to the experimenter $(M=3.77, S D=1.46), t(43)=-1.974, p=.05$; lower responsibility to the victim $(M=.70, S D=1.11)$ than to themselves, $t(43)=-8.15, p<.001$; and lower responsibility to the victim than to the experimenter, $t(43)=-10.21, p<.001$.

\section{Discussion}

\section{Obedience Rates}

Recent social psychology research suggests that participants refuse to obey direct orders (Burger et al., 2011) probably because its use by authority dismantles the group relationship between participants and authority (Reicher \& Haslam, 2011). At the same time, analyses of recent crimes of obedience emphasized on the important role of coercive pressure (e.g., Lankford, 2009). We found a higher level of obedience in the "Compliance with pressure" condition than in the "Compliance without pressure," which seems to support the view that coercive pressure is a key component of the obedience process. However, a striking result is the high level of obedience we obtained in the "Compliance without pressure" condition.

\section{Breaking Points}

Several studies suggest a "breaking point" in the Milgram procedure at $150 \mathrm{~V}$, that is when participants first heard the learner complain about the pain and demand to be released. Indeed, "this point was the most likely place for participants to refuse to continue" (Burger et al., 2011; see also Burger, 2009; Packer, 2008). And recent research using the administrative obedience experiment found a similar breaking point (participants disobeyed when the victim asked for the experiment to stop; Bocchiaro \& Zimbardo, 2010). In our study, the victim first asked to stop the experiment at Remark 8 ("Please stop, I cannot concentrate because of you"), and his first verbal protest occurred at Remark 6 ("I am doing my best"). While Remark 8 should be the most likely point for participants to disobey, disobedience in the "Compliance without pressure" condition occurred at Remark 6 (before the victim asked to stop the experiment) or even before. In contrast, the disobedient participant in "compliance with pressure" condition disobeyed at Remark 10. As emphasized by Reicher and Haslam (2011), "the whole dilemma and the whole drama of the paradigm lies in the fact that participants are torn between different relationships, different obligations, different moralities. Mostly, these pit obligations to the experimenter against obligations to the learner." Our results could suggest the existence of two different "patterns of disobedience": (i) under a high level of coercive pressure, the victim's demands to be released are a condition at which disobedience occurs, (ii) under a low level of coercive pressure participants are more able to disobey even before the victim's demands to stop the experiment.

\section{Conclusion}

Our results suggest that coercive pressure is not necessary to engage people in a process of destructive obedience. However, a higher level of coercive pressure appears to be related to a higher level of obedience. According to Bandura (2002), the Milgram studies revealed that the greater the legitimization and closeness of authority issuing injurious commands, the higher the obedient aggression. We believe that the former argument (legitimization) was satisfied in the "Compliance without pressure" condition, while the latter (closeness) was satisfied in the "Compliance with pressure" condition. This could constitute a starting point for further studies investigating the relative importance of both factors but also, beyond the agentic state, the importance of shared norms between the

1 We performed nonparametric tests when the outcome did not follow a normal distribution. 
participant and the authority during this process (Haslam \& Reicher, 2012).

\section{Acknowledgments}

This work was supported by the Institut Universitaire de France to Martial Mermillod. We thank Alain Méot for useful comments on the manuscript and Julien Brun for his help in conducting the experiment.

\section{References}

Bandura, A. (2002). Social Cognitive Theory in Cultural Context. Applied Psychology: An International Review, 51, 269-290.

Berkowitz, L. (1999). Evil is more than banal: Situationism and the concept of evil. Personality and Social Psychology Review, 3, 246-253.

Blascovich, J., Loomis, J., Beall, A., Swinth, K., Hoyt, C., \& Bailenson, J. N. (2002). Immersive virtual environment technology as a methodological tool for social psychology. Psychological Inquiry, 13, 103-104.

Bocchiaro, P., \& Zimbardo, P. (2010). Defying unjust authority: An exploratory study. Current Psychology, 29, 155-170.

Brunet, A., Weiss, D., Metzler, T. J., Best, S. R., Neylan, T. C., \& Rogers, C. (2001). The peritraumatic distress inventory: A proposed measure of PTSD criterion A2. American Journal of Psychiatry, 158, 1480-1485.

Burger, J. (2009). Replicating Milgram: Would people still obey today? American Psychologist, 64, 1.

Burger, J., Girgis, Z., \& Manning, C. (2011). In their own words: Explaining obedience to authority through an examination of participants' comments. Social Psychological and Personality Science, 2, 460-466.

Cheetham, M., Pedroni, A. F., Antley, A., Slater, M., \& Jäncke, L. (2009). Virtual Milgram: Empathic concern or personal distress? Evidence from functional MRI and dispositional measures. Frontiers in Human Neuroscience, 3, 1-10.

Dambrun, M., \& Vatiné, E. (2010). Reopening the study of extreme social behaviors: Obedience to authority within an immersive video environment. European Journal of Social Psychology, 40, 760-773.

Elias, N. (1983). The Court Society. Oxford, UK: Blackwell.

Enzle, M., \& Harvey, M. (1982). Rhetorical request for help. Social Psychology Quarterly, 45, 172-176.

Gibson, S. (2013). Milgram's obedience experiments: A rhetorical analysis. The British Journal of Social Psychology, 52, 290-309.

Gross, A. E., \& Fleming, I. (1982). Twenty years of deception in social psychology. Personality and Social Psychology Bulletin, 8, 402-408.

Haslam, S. A., \& Reicher, S. D. (2012). Contesting the "Nature" of Conformity: What Milgram and Zimbardo's studies really show. PLoS Biology, 10, e1001426.

Hertwig, R., \& Ortmann, A. (2008). Deception in experiments: Revisiting the arguments in its defense. Ethics \& Behavior, $18,1-34$.

Kelman, H. C. (2006). The policy context of torture: A socialpsychological analysis. International Review of the Red Cross, 87(857), 123-134.
Kelman, H. C., \& Hamilton, V. L. (1989). Crimes of obedience: Toward a social psychology of authority and responsibility. New Haven, CT/London, UK: Yale University Press.

Lankford, A. (2009). Promoting aggression and violence at Abu Ghraib: The US Military's Transformation of ordinary people into torturers. Aggression and Violent Behavior, 14, 388-395.

Meeus, W., \& Raaijmakers, Q. (1986). Administrative obedience: Carrying out orders to use psychological-administrative violence. European Journal of Social Psychology, 16, 311-324.

Meeus, W., \& Raaijmakers, Q. (1995). Obedience in modern society: The Utrecht studies. Journal of Social Issues, 51, 155-175.

Milgram, S. (1963). Behavioral study of obedience. Journal of Abnormal and Social Psychology, 67, 371-378.

Milgram, S. (1974). Obedience to authority: An experimental view. New York, NY: Harper \& Row.

Miller, A. G. (1986). The obedience experiments: A case study of controversy in social science. New York, NY: Praeger.

Packer, D. (2008). Identifying systematic disobedience in Milgram's obedience experiments: A meta-analytic review. Perspectives on Psychological Science, 3, 301-304.

Reicher, S. D., \& Haslam, S. A. (2011). After shock? Toward a social identity explanation of the Milgram "obedience" studies. The British Journal of Social Psychology, $50,163-169$.

Reicher, S. D., Haslam, S. A., \& Smith, J. R. (2012). Working towards the experimenter: Reconceptualizing obedience within the Milgram paradigm as identification-based followership. Perspectives on Psychological Science, 7, 315-324.

Slater, M., Antley, A., Davison, A., Swapp, D., Guger, C., Barker, C., ... Sanchez-Vives, M. V. (2006). A virtual reprise of the Stanley Milgram obedience experiments. PloS One, $1,1-10$.

Weiss, D. J. (2001). Deception by researchers is necessary and not necessarily evil. Behavioral and Brain Sciences, 24, 431-432.

Werhane, P., Pincus Hartman, L., Archer, C., Englehardt, E. E., \& Pritchard, M. S. (2013). Obstacles to ethical decisionmaking: Mental models, Milgram and the problem of obedience. Cambridge, UK: Cambridge University Press.

Received January 23, 2014

Revision received April 8, 2015

Accepted June 9, 2015

Published online December 7, 2015

Martial Mermillod

Department of Psychology

Laboratoire de Psychologie et NeuroCognition

(CNRS UMR 5105)

Grenoble University

38040 Grenoble Cedex

France

Tel. +33 4 7682-5893

E-mail Martial.Mermillod@upmf-grenoble.fr 